\title{
Histoquímica e ultra-estrutura da ontogênese dos tetrasporângios de Hypnea musciformis (Wulfen) J. V. Lamour. (Gigartinales, Rhodophyta)
}

\author{
ZENILDA LAURITABOUZON ${ }^{1}$
}

(recebido: 21 de janeiro de 2005; aceito: 23 de março de 2006)

\begin{abstract}
Histochemistry and ultrastructure of the ontogenesis of the tetrasporangia of Hypnea musciformis (Wulfen) J. V. Lamour. (Gigartinales, Rhodophyta)). Tetraspore development was studied in Hypnea musciformis (Wulfen) J. V. Lamour. using light and electron microscopes, and techniques of histochemistry. Tetrasporangial differentiation arises from a cortex cell that enlarges. This cell undergoes mitosis to form a tetrasporangial mother cell and a stalk cell. The histochemichal study indicated that the cell wall layers are composed mainly of acidic polysaccharides, reacting with toluidine blue $\mathrm{O}$, alcian blue and alcian yellow. The tetrasporangial mother cell is also stained with periodic acid Schiff, that detect neutral carbohydrates, and with coomassie brilliant blue, that detect proteins. The transformation of cortical cells into mature tetrasporangia involves a series of structural changes, especially of the chloroplasts and dictyosomes. The tetrasporangial mother cell rapidly becomes elongated, and a distinctive cell wall is formed before the onset of meiosis. During this elongation phase there is also an increase in the number of chloroplasts. The meiotic tetrasporocyte is characterized by extensive development of the perinuclear endoplasmic reticulum. Throughout meiosis, there is a continuous replication of chloroplasts as well as a synthesis of starch and the formation of vesicles with electron-dense contents. Cytokinesis begins with the formation of the cleavage furrow, produced by the infurrowing of the plasma membrane. This cleavage furrow formation is followed by mucilage deposition surrounding the tetraspores.
\end{abstract}

Keys words - polysaccharides, subcellular organization, tetrasporogenesis

RESUMO - (Histoquímica e ultra-estrutura da ontogênese dos tetrasporângios de Hypnea musciformis (Wulfen) J. V. Lamour. (Gigartinales, Rhodophyta)). O desenvolvimento dos tetrásporos de Hypnea musciformis (Wulfen) J. V. Lamour. foi estudado com o uso dos microscópios de luz e eletrônico. Os tetrasporângios diferenciam-se a partir de células corticais. Essas células sofrem mitose dando origem à célula-mãe do tetrasporângio e à célula suporte. As técnicas histoquímicas indicam que a parede celular do tetrasporângio é composta especialmente de polissacarídeos ácidos, reagindo com azul do toluidina O, azul de alcião e amarelo de alcião. Os tetrasporângios são também corados com ácido periódico de Schiff, para carboidratos neutros, e com azul brilhante de coomassie, para proteínas. A transformação da célula cortical em célula mãe do tetrasporângio envolve uma série de mudanças estruturais, especialmente dos cloroplastos e dictiossomos. A célula-mãe do tetrasporângio alonga-se rapidamente e uma parede celular espessa é produzida antes da meiose. Durante essa fase de crescimento ocorreu aumento significativo no número de cloroplastos, grãos de amido e vesículas osmiofílicas. O tetrasporângio meiótico é caracterizado pelo desenvolvimento extensivo do retículo endoplasmático perinuclear. A citocinese tem início com a formação do sulco de divisão, formado pela invaginação da membrana plasmática. Concomitante à invaginação da membrana ocorre a deposição de mucilagem em torno dos tetrásporos.

Palavras-chave - organização subcelular, polissacarídeos, tetrasporogênese

\section{Introdução}

O gênero Hypnea (Gigartinales, Rhodophyta) é largamente distribuído pelas costas tropicais e subtropicais, sendo Hypnea musciformis (Wulfen) J. V. Lamour. a espécie mais conhecida do gênero, encontrada em muitas regiões do Oceano Atlântico (Taylor 1960), Oceano Índico (Ramarao 1970, Mshigeni \& Lorri 1977) e Oceano Pacífico (Chapman 1971,

1. Universidade Federal de Santa Catarina, Centro de Ciências Biológicas, Departamento de Biologia Celular, Embriologia e Genética, Campus Universitário, Trindade, 88040-900 Florianópolis, SC, Brasil.zenilda@ccb.ufsc.br
Mshigeni \& Lorri 1977). Também apresenta ampla distribuição ao longo do litoral brasileiro (Oliveira 1977). Seus representantes reproduzem-se sexuada e assexuadamente, sendo a fecundação seguida por duas gerações assexuadas que produzem esporos, denominadas gerações carposporofítica e tetrasporofítica. A principal característica diagnóstica dessa espécie é a presença de processo em forma de ganchos nas porções terminais dos eixos principais, cuja função é fixar como gavinhas, a alga sobre outras algassuporte ou outros substratos (Fritsch 1965). Devido à importância econômica, essa espécie tem sido estudada sob vários aspectos tais como: reprodução, produção de carragenana e teor de ficocolóide (Mshigeni 1976a, b, c, Freidlander \& Zelikovitch 1984). No Brasil, alguns 
estudos referentes a essa espécie envolvem a produção de carragenana (Berchez \& Oliveira 1990, Saito \& Oliveira 1990).

Os polissacarídeos que impregnam a parede celular, tais como a carragenana, estão envolvidos na permeabilidade seletiva das células. Esses polissacarídeos sulfatados, quando presentes nas algas que vivem na zona entre-marés, supostamente protegem-nas contra a dessecação durante as marés baixas (Tripodi \& De Masi 1975). Na parede celular das células reprodutivas, esses polissacarídeos, pela sua natureza higroscópica, desempenham também um importante papel na liberação dos esporos e gametas (McCully 1966, Evans et al. 1973, Bouzon et al. 2000).

Vários aspectos da ultra-estrutura da tetrasporogênese têm sido abordados em alguns grupos de algas vermelhas, principalmente em membros da Ceramiales (Kugrens \& West 1972, Scott \& Dixon 1973, Alley \& Scott 1977, Santisi \& De Masi 1981, Vesk \& Borowitska 1984, Tsekos et al. 1985), além de alguns estudos envolvendo outras ordens (Pueschel 1979 e 1982, Gori 1982, Delivopoulos 2004). Entretanto, não foram encontrados na literatura estudos semelhantes na ordem Gigartinales e, dessa forma, o presente trabalho tem como objetivo fornecer informações sobre a tetrasporogênese de Hypnea musciformis pertencente a esta ordem.

\section{Material e métodos}

Plantas tetraspofíticas de H. musciformis (Wulfen) J. V. Lamour. foram coletadas nas praias dos Ingleses e Ponta do Sambaqui - Florianópolis, SC, Brasil. Porções férteis, denominadas estiquídios, foram fixadas em solução de paraformaldeído 2,5\% em tampão fosfato 0,2 M, pH 7,2, durante seis a oito horas, à temperatura de $4{ }^{\circ} \mathrm{C}$. Após a fixação, o material foi desidratado em concentrações crescentes de etanol e infiltrado com historesina glicolmetacrilato (GMA) (Arnold et al. 1975, modificado). As seç̧ões foram feitas em micrótomo de rotação Reichert equipado com navalha de aço. Para observação em microscopia de luz, as secções com espessuras de 2-5 $\mu$ m, foram coradas com solução aquosa a $1 \%$ de azul de anilina acidificada com $\mathrm{HCl}$ a $1 \mathrm{~N}$. Algumas secções foram também submetidas a vários testes histoquímicos: azul de toluidina O (ATO) (Gordon \& McCandless 1973), pH 3,0, para observar polissacarídeos ácidos, cujo controle foi feito elevando o pH para 6,0 com a adição de $\mathrm{NaOH} 1 \mathrm{~N}$; azul de alcião (AB), para polissacarídeos sufatados; amarelo de alcião (AY), para polissacarídeos carboxilados (La Clarie \& Dawes 1976, Ravetto 1964), cujo controle também foi feito com a elevação do pH com $\mathrm{NaOH} 1 \mathrm{~N}$. Para observar polissacarídeos neutros foi utilizada a reação com ácido periódico de Schiff
(PAS), o controle da reação de PAS foi feito com a acetilação do material ou pela omissão da oxidação pelo ácido periódico. Para observar proteínas totais foi utilizado azul brilhante de coomassie (CBB) (Gahan 1984). O material foi analisado e fotografado em microscópio de luz (ML) Olympus modelo BH-2, equipado com câmara fotográfica Olympus modelo $\mathrm{C}-35 \mathrm{AD}$.

Os estiquídíos foram isolados do talo e fixados em solução de Karnovsky (1965) modificada, tamponada com cacodilato $0,2 \mathrm{M}$ (pH 7,2), durante duas horas, em temperatura ambiente, para análise ultra-estrutural. O material foi lavado três vezes no mesmo tampão (30 min. cada) e pós-fixado em tetróxido de ósmio 2\% durante duas horas. Após serem lavados novamente no mesmo tampão, os estiquídios foram desidratados em uma série de concentrações crescentes de acetona (30 min. em cada concentração), infiltrados em séries graduais de acetona-resina Spurr durante três dias, seguido duas infiltrações em resina pura (12 horas) e polimerizados em estufa a $70{ }^{\circ} \mathrm{C}$ por 24 horas. Os cortes ultrafinos foram feitos com navalha de diamante em ultramicrotómo PorterBlum e, posteriormente, contrastados com acetato de uranila $1 \%$ e citrato de chumbo $1 \%$. Os cortes ultra-finos foram observados e fotografados no microscópio eletrônico de transmissão Zeiss EM 900.

\section{Resultados}

Microscopia de luz - A planta tetraspofítica de H. musciformis (Wulfen) J. V. Lamour. é formada por um talo cilíndrico, abundantemente ramificado e com eixos principais revestidos por numerosos ramos curtos espinescentes (figura 1). Esses ramos tornam-se dilatados na base após a diferenciação dos tetrasporângios e são denominados estiquídios (figura 2). Os tetrasporângios se diferenciam a partir das células corticais dos estiquídios tornando a região mais pigmentada (figura 3). As células corticais sofrem mitose originando duas diferentes células, a célula basal e a célula-mãe do tetrasporângio. Quando jovem a célulamãe do tetrasporângio mantém contato por algum tempo com a célula basal por meio da conexão intercelular (figura 4). A célula-mãe do tetrasporângio gradativamente torna-se alongada, perdendo o contato com a célula basal (figura 5). Após o aumento de volume da célula-mãe do tetrasporângio, ocorre o processo de meiose resultando em duas e posteriormente quatro células-filhas haplóides, os tetrásporos divididos zonadamente, no qual a primeira clivagem é mediana formando duas células-filhas, seguidas por outras duas divisões, paralelas a primeira, formando quatro célulasfilhas (figuras 6, 7). A liberação dos tetrásporos ocorre após a ruptura da parede do tetrasporângio, ficando o 
remanescente como uma cavidade vazia (figura 7). Embora a diferenciação da célula cortical até a formação tetrasporângio maduro ocorra num processo dinâmico e contínuo, algumas alterações podem ser destacadas durante a maturação tais como: proliferação de organelas, síntese de amido das florídeas e granulações de natureza ácida no citoplasma.

Tanto nos tetrasporângios em maturação quanto nos maduros, quando tratados com azul de toluidina, a matriz extracelular e o componente microfibrilar da parede celular reagem positivamente, revelando a natureza polissacarídica sulfatada desta região (figuras 5-8). Na célula-mãe do tetrasporângio não é observada reação positiva no citoplasma quando corada com azul de toluidina, entretanto os tetrasporângios maduros apresentam granulações indicando síntese de polissacarídeos ácidos com esse corante (figura 8). Quando corados com azul brilhante de coomassie, tanto as células-mãe do tetrasporângio quanto os tetrasporângios maduros apresentam reação positiva restrita ao conteúdo citoplasmático indicando uma proliferação das organelas, especialmente de cloroplastos (figura 9). A maturação caracteriza-se por uma intensa atividade citoplasmática principalmente síntese de material de reserva. Desta forma, quando submetidos à reação de PAS, as células-mãe do tetrasporângio apresentam uma leve reação positiva no conteúdo citoplasmático, sugerindo início da síntese de

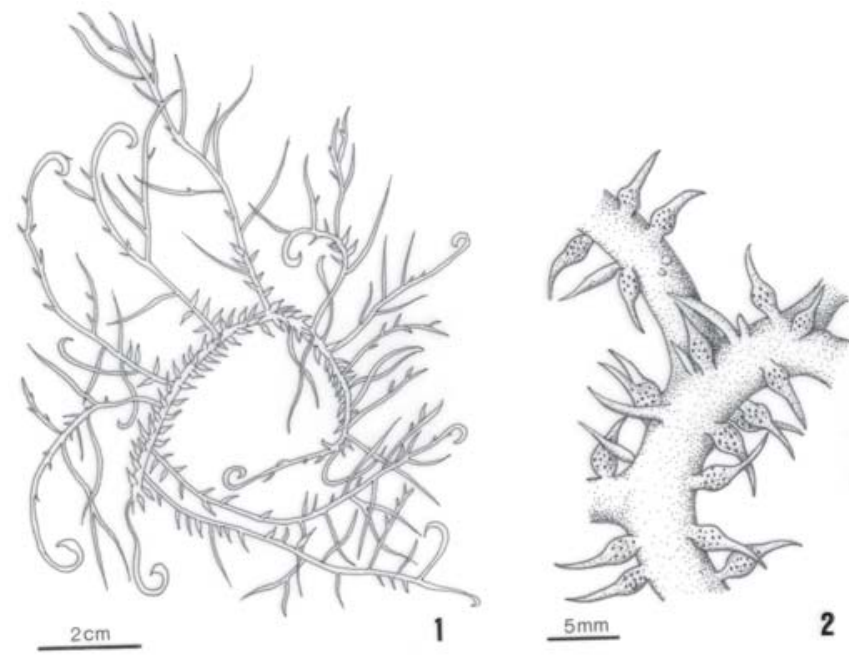

Figuras 1-2. Planta tetrasporofítica de Hypnea musciformis (Wulfen) J. V. Lamour. 1. Aspecto geral da planta. 2. Detalhe do ramo revestido por numerosos ramos curtos férteis, os estiquídios.

Figures 1-2. Tetrasporophytic plant of Hypnea musciformis (Wulfen) J. V. Lamour. 1. General aspect of plant. 2. Detail of a branch covered by numerous fertile short branches, the stichidia. grãos de amido. Com a maturação, a reação de PAS torna-se fortemente positiva, indicando um aumento significativo na síntese desses grãos por todo o citoplasma dos tetrasporângio (figura 10). Quando o material é tratado com azul de alcião e com amarelo de alcião mostra um padrão de coloração similar ao observado na parede celular corada com azul de toluidina (figuras 11, 12). Entretanto, com amarelo de alcião, a reação é também observada no citoplasma como granulações fracamente coradas (figura 11). Por outro lado, todo o material extracelular apresenta reação negativa ao PAS, sugerindo a ausência de polissacarídeos neutros na parede celular.

Microscopia eletrônica - Corroborando as observações feitas ao ML, as células-mãe dos tetrasporângios são derivadas de células corticais e caracterizadas pela presença de um grande núcleo envolvido por retículo endoplasmático rugoso, mostrando um nucléolo bem desenvolvido (figuras 13, 14). Nesse estágio, a célulamãe do tetrasporângio ainda permanece em conexão com a célula basal (figura 15). Os cloroplastos, no início da tetrasporogênese, mostram a mesma organização estrutural observada nas algas vermelhas, com tilacóides simples, paralelos envolvidos por um tilacóide circular e revestidos pela membrana do cloroplasto. O restante do citoplasma é rico em ribossomos livres e, nesse estágio, a presença de corpos elétron-densos é observada no interior do vacúolo. Com a maturação, ocorre uma proliferação maciça de cloroplastos e um concomitante aumento de grãos de amido que são distribuídos por toda a célula (figura 16). Conforme pode ser observado na figura 17, esses cloroplastos apresentam um número reduzido de tilacóides quando comparados ao dos cloroplastos das células vegetativas. Paralelamente ao aumento na quantidade de organelas, começam a ser observadas invaginações da membrana plasmática que virão a dividir o tetrasporângio inicialmente em duas células e, ao mesmo tempo, é depositada mucilagem no espaço entre as células-filhas (figura 16). Grãos de amido das florídeas continuam a ser produzidos e parecem associados com dictiossomos (figura 18). Antes de completar a citocinese, organelas, grãos de amido das florídeas e vesículas derivadas de dictiossomos são espacialmente dispersos entre os esporos. Os processos de divisão prosseguem e quatro esporos uninucleados são formados zonadamente após a finalização do processo meiótico. Entretanto, os sulcos de divisão não são simultâneos. Primeiro formam-se duas células que, posteriormente, se dividem em outras duas sincronicamente ou não (figura 19). Nesse estágio, uma grande quantidade de mucilagem é depositada em torno 
dos esporos, preenchendo o espaço entre as células-filhas (figura 20). Inúmeras vesículas osmiofílicas com 0,2 a $0,3 \mu$ m são observadas próximo da membrana plasmática. No final da maturação, essas vesículas são observadas próximas aos sulcos de divisão e podem estar relacionadas com a produção de mucilagem (figura 20). Durante todo o processo de maturação, os núcleos dos tetrasporângios parecem muito ativos, apresentando grandes nucléolos e cromatina difusa. No final da tetrasporogênese, uma espessa parede celular fibrilar, com diferentes arranjos reticulados das microfibrilas, envolve o tetrasporângio maduro (figura 21).

\section{Discussão}

A tetrasporogênese em Hypnea musciformis (Wulfen) J. V. Lamour. tem início com a diferenciação e conseqüentemente aumento de volume de algumas células da camada cortical que tornam os ramos curtos, que revestem o eixo principal, dilatados e fortemente pigmentados. Essa transformação das células da camada cortical em células reprodutivas tem sido observada nas algas vermelhas (Pueschel 1979).

Nas células das algas, os polissacarídeos são os principais componentes estruturais da parede celular, podendo também desempenhar importante papel de reserva citoplasmática na forma de grãos de amido. Em $H$. musciformis, tanto polissacarídeos neutros quanto sulfatados são detectados nos tetrasporângios por meio de reações histoquímicas. A reação de PAS é utilizada para a identificação de polissacarídeos neutros porque requer a presença de grupos 1,2 glicol que são oxidados para aldeídos pelo ácido periódico (Trick \& Pueschel 1990). Esses grupos são abundantes em polissacarídeos neutros, como por exemplo, os constituintes dos grãos de amido das florídeas, conforme estabelecido por Gordon \& McCandless (1973) em Chondrus crispus Stackhouse, La Claire \& Dawes (1976) em Eucheuma nudum J. Agardh, Young (1979) em Antithamnion defectum Kylin e Pueschel (1979) em Palmaria palmata (L.) Kuntze. A intensa resposta das células reprodutivas de H. musciformis à reação de PAS pode ser atribuída à grande quantidade de grãos de amido citoplasmáticos, que dão um aspecto granular às células submetidas a essa reação. Por outro lado, a parede celular não reage ao PAS indicando a ausência de polissacarídeos neutros na parede celular. Esse fato sugere que a estrutura microfibrilar de parede celular dos tetrasporângios de $H$. musciformis não deve ser constituída por celulose ou a quantidade microfibrilar de celulose é reduzida, não podendo ser detectada com o método utilizado.

O emprego do corante azul de toluidina produz uma reação positiva na parede dos tetrasporângios de $H$. musciformis, revelando a presença de grupos ácidos, o mesmo observado em outras algas vermelhas. Estes resultados estão de acordo com Ramarao (1970) e Saito \& Oliveira (1990), que se referem à presença de carragenana, um polissacarídeo sulfatado de grande interesse comercial em $H$. musciformis. Em pH baixo, os grupos sulfatados são ionizados e por isso pode-se esperar que reação mais intensa, que se observa na parede celular de $H$. musciformis, seja devida à grande concentração de carragenana mais sulfatada. Essa interpretação está baseada na suposição de que a configuração terciária de cada polímero expõe os poliânions sulfatados, formando uma grande quantidade de complexos com azul de toluidina (Gordon \& McCandless 1973). Em H. musciformis, os polissacarídeos sulfatados são também observados no citoplasma dos tetrásporos quando corados com azul de toluidina $\mathrm{pH} 3,0$. A presença de granulações reativas indica que a sulfatação dos polissacarídeos ocorre no meio intracelular. Como a sulfatação de carboidratos é um processo realizado pelos dictiossomos (McCandless \& Craigie 1979), era esperado que reações positivas pudessem ser observadas no citoplasma dos tetrasporângios de $H$. musciformis.

As propriedades de coloração com a reação de alcian foram bem investigadas por Pearse (1968). A técnica, que emprega ambos os corantes (azul de alcião e amarelo de alcião) e que permite distinguir os polissacarídeos exclusivamente sulfatados dos exclusivamente carboxilados, foi introduzida por Ravetto (1964). Em pH 0,5, os grupos carboxila não se dissociam, permitindo que o azul de alcião identifique apenas os grupos sulfatados, enquanto que o amarelo de alcião, em $\mathrm{pH}$ 2,5, reage com os grupos que não reagiram no tratamento anterior. Tal reação permite visualizar em $H$. musciformis uma coloração mais intensa com azul de alcião, como uma fina camada em torno dos tetrasporângios nas mesmas áreas em que reação com azul de toluidina é mais intensa, confirmando a presença de grupos mais sulfatados nessas regiões. $\mathrm{O}$ mesmo padrão de coloração foi obtido por Gordon \& McCandless (1973) e por La Claire \& Dawes (1976) em outras rodofíceas.

As observações confirmam que a tetrasporogênese nas algas vermelhas não implica em profundas alterações na organização ultra-estrutural. Entretanto, quando comparados com os das células vegetativas, os cloroplastos apresentam intensa duplicação, mostrando 

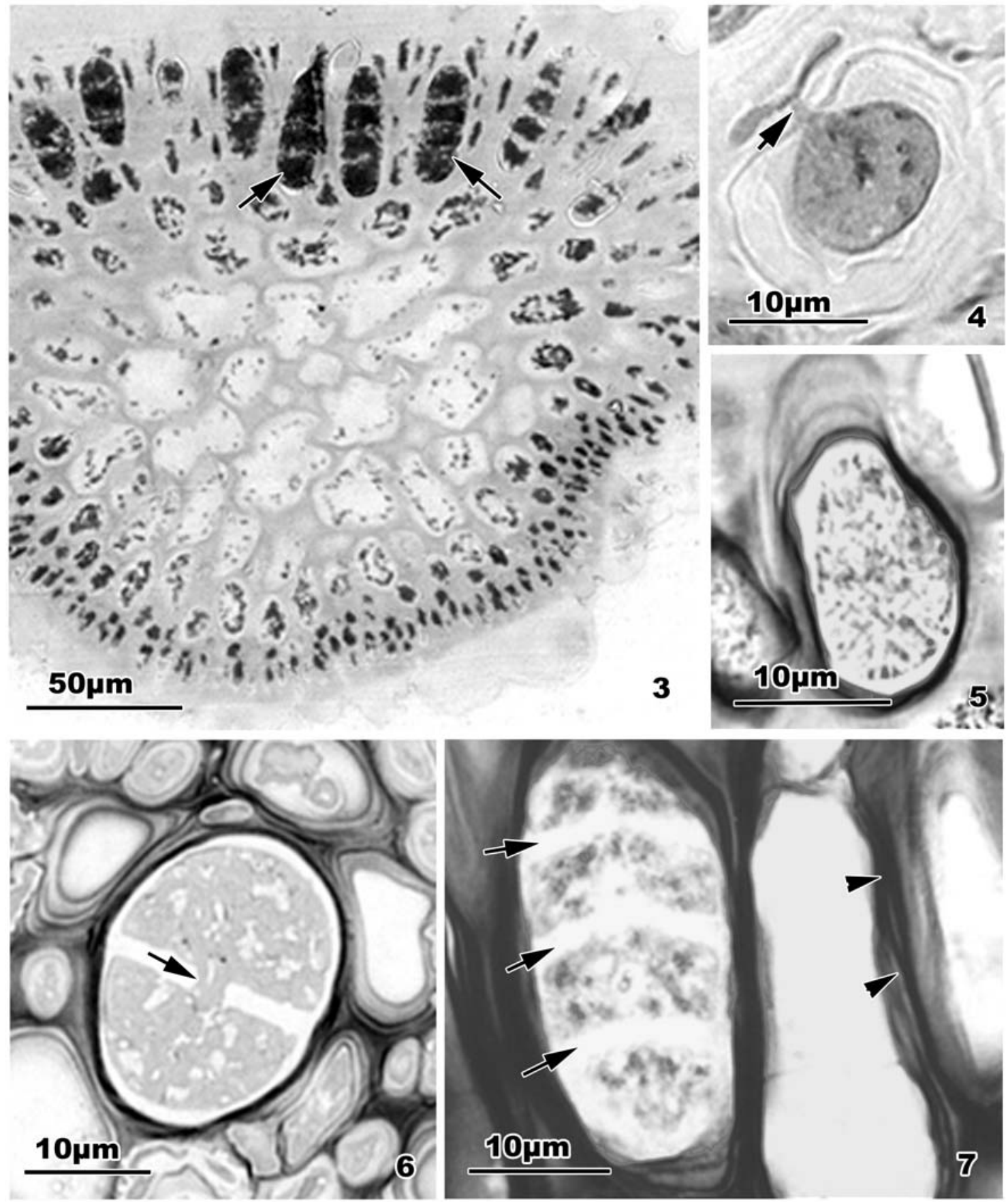

Figuras 3-7. Fases de maturação de tetrasporângios de Hypnea musciformis (Wulfen) J. V. Lamour. observados no ML. 3-6. Cortes transversais. 3. Estiquídio com tetrasporângios maduros (setas). 4. Célula-mãe do tetrasporângio unida à célula basal por conexão intercelular (seta). 5. Célula-mãe do tetrasporângio em maturação antes da divisão celular. 6. Célula-mãe do tetrasporângio: primeira citocinese meiótica por invaginação da membrana plasmática (seta). 7. Corte longitudinal de um tetrasporângio maduro pós-meiótico com divisão zonada dos tetrásporos (setas) e parede celular remanescente após a liberação dos tetrásporos (cabeças de setas).

Figures 3-7. Maturation phases of tetrasporangia of Hypnea musciformis (Wulfen) J. V. Lamour. observed under LM. 3-6. Transversal sections. 3. Stichidia with mature tetrasporangia (arrows). 4. Tetrasporangia mother cell linked to a base cell by a pit-connection (arrow). 5. Tetrasporangia mother cell before cell division. 6 . Tetrasporangia mother cell: first meiotic division by the infurrowing of plasma membrane (arrow). 7. Longitudinal section of a mature post-meiotic tetrasporangium with zonate division of tetraspores (arrows) and remaining cell wall after tetraspore release (arrowheads). 


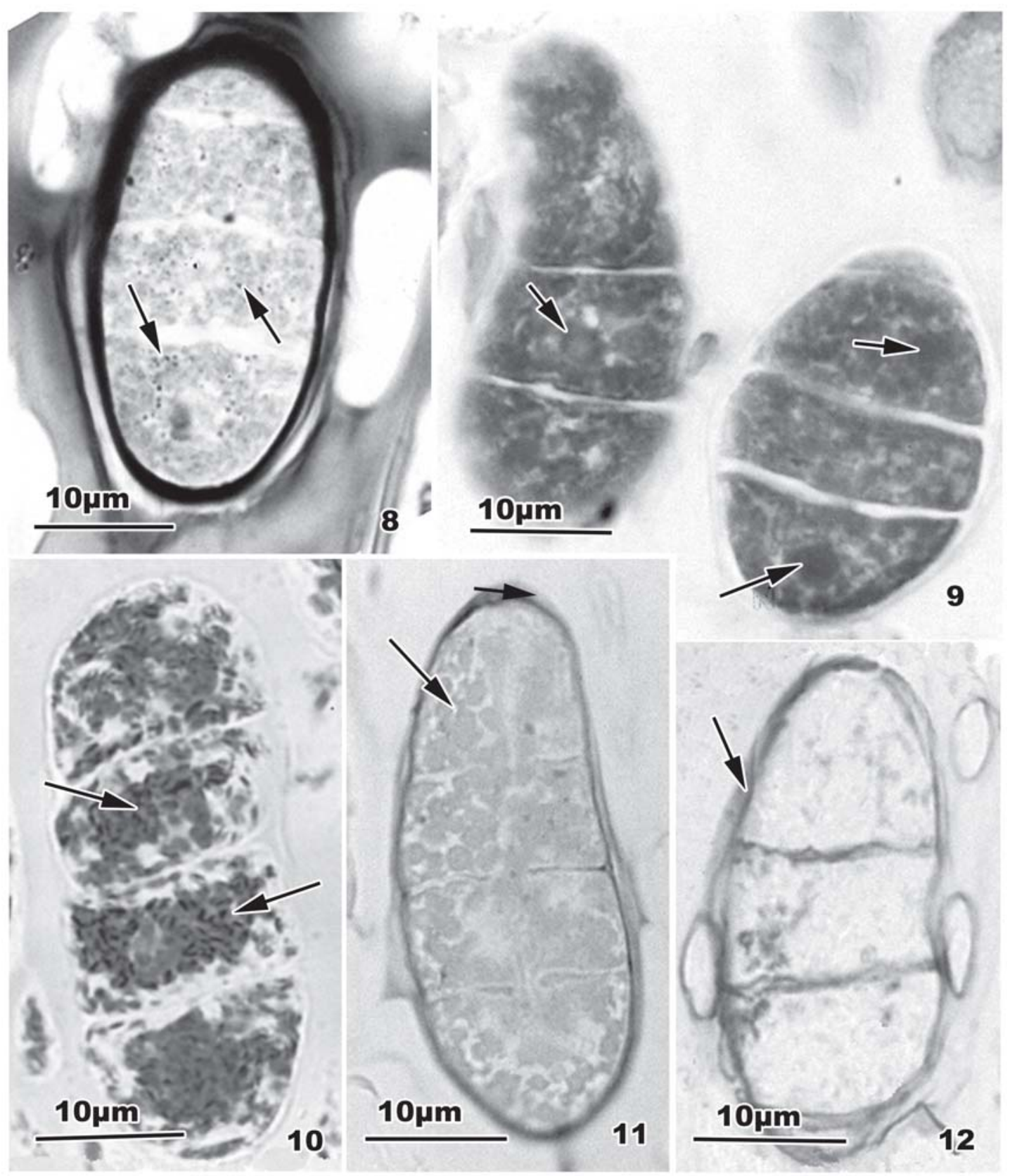

Figuras 8-12. Tetrasporângios maduros de Hypnea musciformis (Wulfen) J. V. Lamour. submetidos a vários tratamentos histoquímicos. 8. Tetrasporângio corado com azul de toluidina com reação mais intensa na parede celular. Presença de finas granulações no citoplasma dos tetrásporos (setas). 9. Tetrasporângios corado com azul brilhante de coomassie, apresentando intensa coloração restrita ao citoplasma e núcleo evidente localizado na região central de cada tetrásporo (setas). 10. Tetrasporângio corado com PAS com reação fortemente positiva restrita ao citoplasma, evidenciando os numerosos grãos de amido (setas). 11. Tetrasporângio corado com amarelo de alcião com reação positiva para a parede tetrasporangial e para o conteúdo citoplasmático (seta). 12. Tetrasporângio corado com azul de alcião com reação fortemente positiva para a parede celular (seta).

Figures 8-12. Mature tetrasporangium of Hypnea musciformis (Wulfen) J. V. Lamour. submitted to different histochemical reactions. 8. Toluidine blue-stained tetrasporangium with intense reaction at the cell wall. Fine granulations at the cytoplasm of tetraspores are shown (arrows). 9. Tetrasporangia stained with coomassie brilhant blue showing intense reaction restricted to the cytoplasm and evident nucleus located in the central region of each tetraspore (arrows). 10. PAS-stained tetrasporangium with strongly positive reaction restricted to the cytoplasm, indicating numerous starch grains (arrows). 11. Alcian yellowstained tetrasporangium with positive reaction at the tetrasporangial wall and in the cytoplasmic content (arrow). 12. Alcian blue-stained tetrasporangium with strongly positive reaction at the cell wall (arrow). 


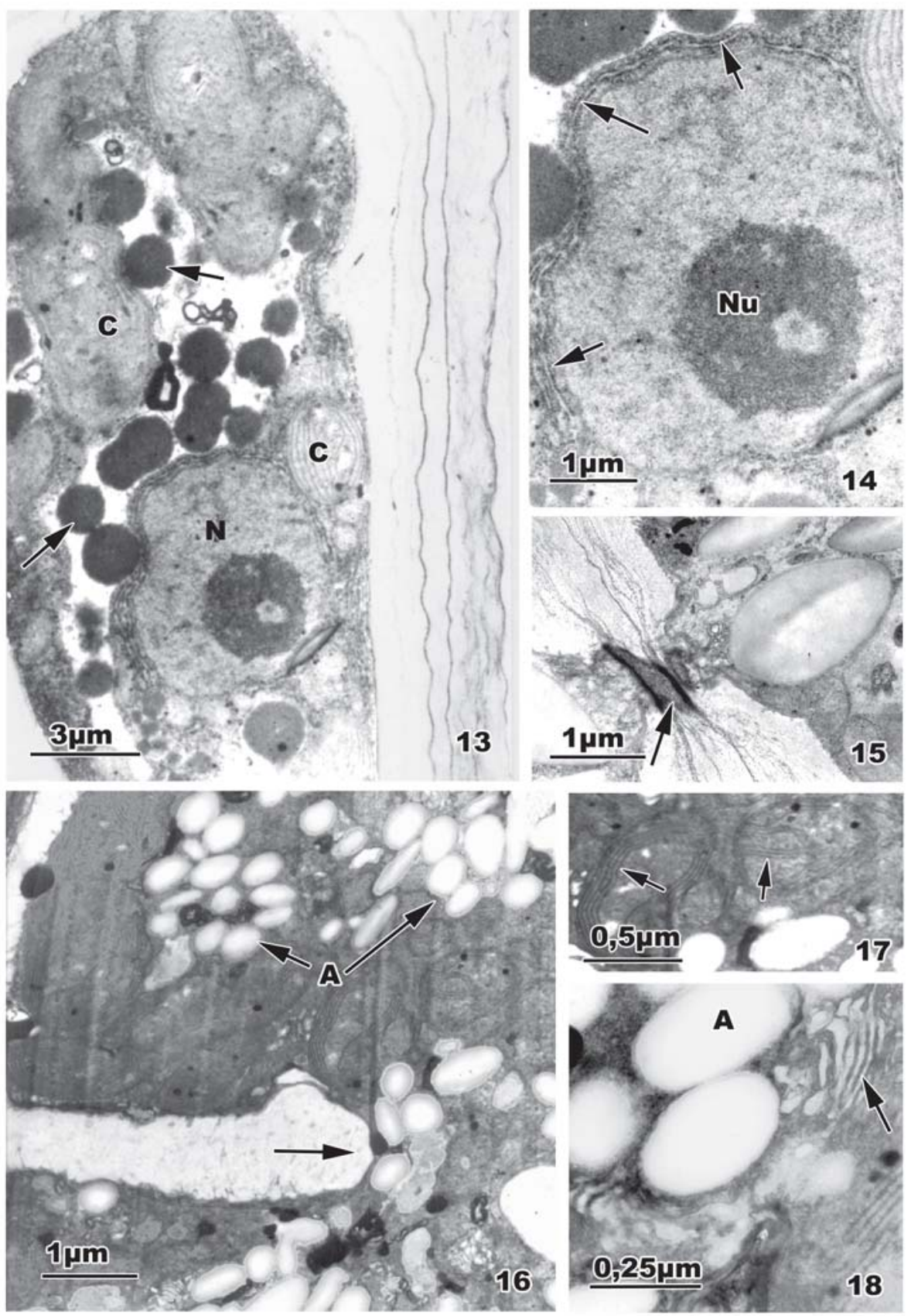

Figuras 13-18. Estágios de maturação de tetrasporângios de Hypnea musciformis (Wulfen) J. V. Lamour. observados no MET. 13. Corte longitudinal da célula-mãe do tetrasporângio com núcleo $(\mathrm{N})$ e alguns cloroplastos (C). Grânulos elétron-densos no vacúolo (setas). 14. Núcleo da célula-mãe do tetrasporângio com nucléolo $(\mathrm{Nu})$ bem desenvolvido e retículo endoplasmático perinuclear (setas). 15. Conexão intercelular entre a célula-mãe do tetrasporângio e a célula-basal. 16. Clivagem inicial do tetrasporângio com processo de invaginação centrípeta da membrana plasmática (seta) e presença de grãos de amido (A). 17. Cloroplastos de tetrasporângios destacando a redução de tilacóides (setas). 18. Citoplasma do tetrasporângio com grãos de amido (A) em associação com dictiossomos (seta).

Figures 13-18. Maturation stages of tetrasporangia of Hypnea musciformis (Wulfen) J. V. Lamour. observed under TEM. 13. Longitudinal section of tetrasporangial mother cell with nucleus $(\mathrm{N})$ and some chloroplasts (C). Electron-dense granules in the vacuole (arrows). 14. Nucleus of tetrasporangial mother cell with well-developed nucleolus ( $\mathrm{Nu}$ ) and perinuclear endoplasmic reticulum (arrows). 15. Pit connection between the tetrasporangial mother cell and the basal cell. 16. Initial cleavage of the tetrasporangium by centripetal invagination of the plasma membrane (arrow) and starch grains (A). 17. Chloroplasts of tetrasporangium with reduced number of thylakoids (arrows). 18. Starch grains associated with dictyosomes within the tetrasporangial cytoplasm (arrow). 
um número reduzido de tilacóides. Essa redução no número de tilácóides deve ser decorrente do processo rápido de reprodução dessas organelas.

Na fase final de maturação dos tetrasporângios, inúmeras vesículas com conteúdo osmiofílico são observadas próximas à membrana plasmática. Essas vesículas são produzidas pelos dictiossomos na fase final de maturação dos tetrásporos (Alley \& Scott 1977, Tsekos et al. 1985, Delivopoulos 2004) e ocorrem especialmente nas regiões de invaginação da membrana, durante os processos de citocinese. Estas vesículas devem contribuir com material para a formação da mucilagem que envolve cada tetrásporo. A deposição dessa mucilagem deve ocorrer por exocitose após a fusão das vesículas com a membrana plasmática formando uma camada espessa em torno de cada tetrásporo. Na tetrasporogênse de $H$. musciformis, essa mucilagem deve estar relacionada com a liberação de tetrásporos, considerando que a liberação das células reprodutivas nas algas vermelhas está associada à hidratação do envoltório mucilaginoso presente entre a membrana plasmática e a parede celular (Bouzon et al. 2000). Em H. musciformis a liberação dos tetrásporos ocorre após a ruptura da parede celular que envolve o tetrasporângio maduro, ficando o remanescente da parede como uma cavidade vazia no estiquídio.

A parede celular externa que envolve os tetrasporângios maduros de $\mathrm{H}$. musciformis mostra uma textura microfibrilar, com microfibrilas estruturadas em camadas de diferentes graus de compactação. Essa organização estrutural foi descrita em várias outras rodofíceas (Chamberlain \& Evans 1973, KonradHawkins 1974, Borowitzka \& Vesk 1978, Young 1980, Mariani et al. 1990), mas o mecanismo da deposição seqüencial das camadas da parede não é conhecido. Em Enteromorpha intestinalis (L.) Link, a formação de camadas pode ser conseqüência das diferenças de concentração do material fibrilar que é possivelmente originado dos dictiossomos (McArthur \& Moss 1977). Young (1980) e Ramm-Anderson \& Wetherbee (1982)
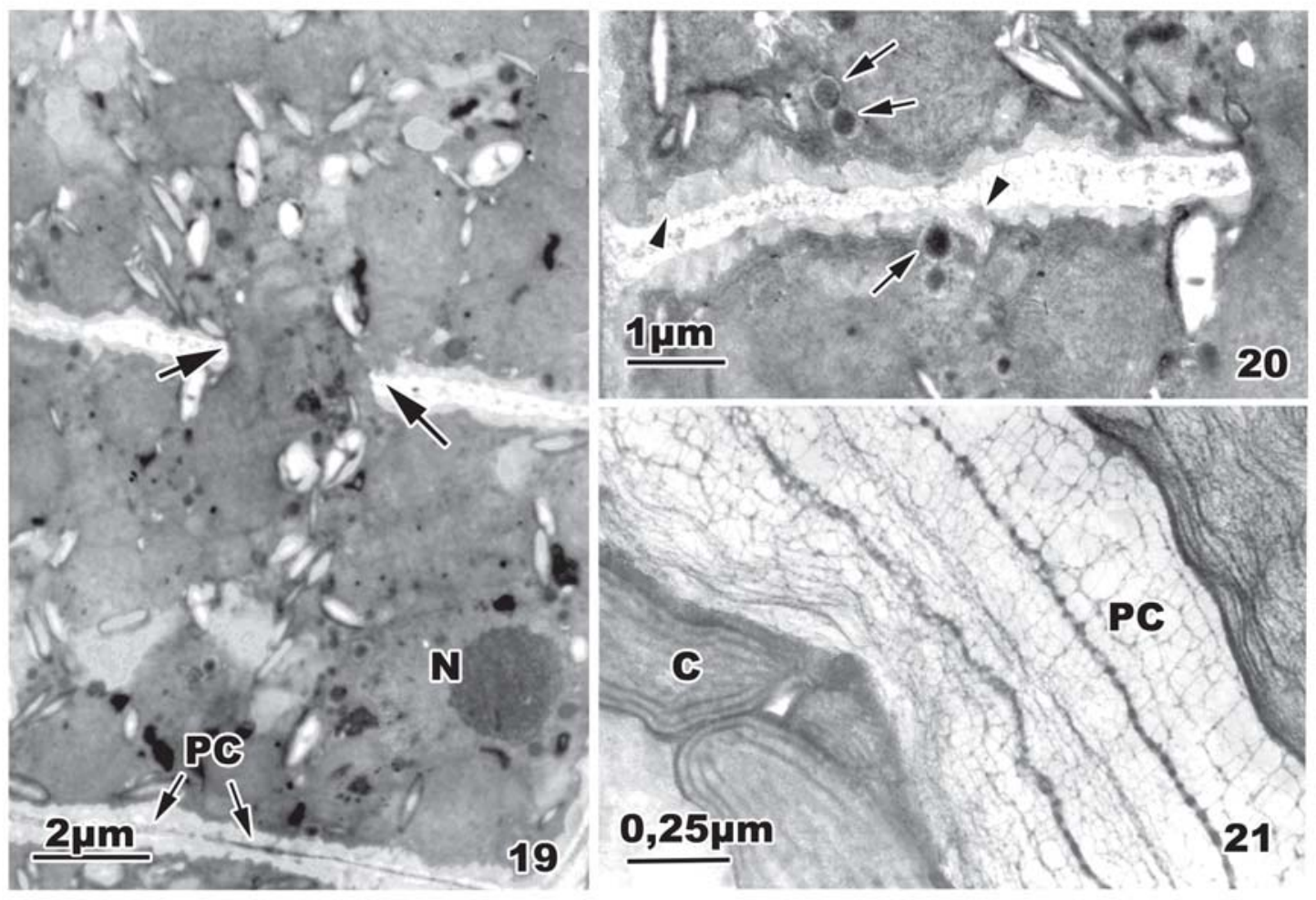

Figuras. 19-21. Tetrasporângio de Hypnea musciformis (Wulfen) J. V. Lamour. ao MET. 19. Divisão de tetrásporos não sincronizada. Segunda citocinese meiótica (setas). 20. Vesículas osmiofílicas (setas) próximas à membrana plasmática. 21. Parede celular (PC) do tetrasporângio com camadas de aspecto reticulado, envolvidas por microfibrilas paralelas.

Figures. 19-21. Tetrasporangium of Hypnea musciformis (Wulfen) J. V. Lamour. under TEM. 19. Tetraspores with nonsynchronized division. Second meiotic division (arrows). 20. Cored vesicles (arrows) close to the plasma membrane. 21. Cell wall (PC) of the tetrasporangium with layers of reticulated aspect surrounded by parallel microfibrils. 
sugerem também que as vesículas provenientes dos dictiossomos estão envolvidas na formação da parede celular de Antithamnion defectum Kylin e Nemalion helminthoides (Velley) Batters, respectivamente. Os dictiossomos mostram uma marcada atividade que envolve a produção e secreção de carboidratos complexos. Considerando que nas algas vermelhas a polimerização dos grãos de amido é externa aos cloroplastos, nos tetrasporângios de $H$. musciformis, esses grãos são observados próximos às cisternas dos dictiossomos, sugerindo que essas organelas contribuem para a formação dos grãos de amido das florídeas. Segundo Kugrens \& West (1972), os dictiossomos parecem também estar relacionados com a formação dos grãos de amido nos tetrásporos de Erythrocystis saccata Agardh. Nos estágios finais da maturação dos tetrasporângios, o número de grãos de amido aumenta consideravelmente e essa produção maciça de material de reserva deve ser utilizada nos eventos relacionados com as fases iniciais da germinação dos tetrásporos (Ouriques \& Bouzon 2003).

O núcleo inicialmente parece envolto por retículo endoplasmático granular, sugerindo intensa atividade metabólica nos tetrasporângios em maturação. As atividades de síntese são reforçadas pela presença de grandes nucléolos durante toda a tetrasporogênese. Porém, a divisão nuclear não foi observada durante a maturação dos tetrasporângios de $H$. musciformis sugerindo que esse evento ocorra rapidamente quando comparado com as demais atividades citoplasmáticas.

\section{Referências bibliográficas}

ALLEY, C.D. \& SCOTT, J.L. 1977. Usual dictyosome morphology and vesicle formation in tetrasporangia of the marine red alga Polysiphonia denudata. Journal of Ultrastructure Research 58:289-298.

ARNOLD, W., MITRENGA, D. \& MAYERSBACH, H. 1975. Gefriertrocknung und einbsttung in glycolmethacrylat (GMA) - ergehnisse histochemischer reaktion. Acta Histochemistry 14:271-277.

BERCHEZ, F.A.S. \& OLIVEIRA, E.C. 1990. Maricultural essays with the carragenophyte Hypnea musciformis in São Paulo. In Cultivation of seaweed in Latin America (E.C. Oliveira \& N. Kautsky, eds.).Universidade de São Paulo, São Paulo, p.89-94.

BOROWITZKA, M.A. \& VESK, M. 1978. Ultrastructure of the corallinaceae. I. The vegetative cells of Corallina officinalis and C. cuvierii. Marine Biology 46:295-302.

BOUZON, Z.L., MIGUENS, F. \& OLIVEIRA, E.C. 2000. Male gametogenesis in the red algae Gracilaria and Gracilariopsis (Rhodophyta, Gracilariales). Cryptogamie Algologie 21:33-47.
CHAMBERLAIN, A.H.L. \& EVANS, L.V. 1973. Aspects of spore production in the red alga Ceramnium. Protoplasma 76:138-159.

CHAPMAN, V.J. 1971. The marine algae of Fiji. Revue Algologique 10:164-171.

DELIVOPOULOS, S.G. 2004. Ultrastructure of tetrasporogenesis in the red alga Rhodymenia californica var. attenuata (Rhodymeniaceae, Rhodymeniales, Rhodophyta). Botanica Marina 47:222-230.

EVANS, L.V., SIMPSON, M. \& CALLOW, M.E. 1973. Sulphated polysaccharide synthesis in brown algae. Planta 110:237-252.

FREIDLANDER, M. \& ZELIKOVITCH, N. 1984. Growth rates, phycocolloid yield and quality of the red seaweeds, Gracilaria sp, Pterocladia capillacea, Hypnea musciformis and H. cornuta. Acquaculture 40:57-66.

FRITSCH, F.E. 1965. The structure and reproduction of the algae. Cambridge University Press, Cambridge.

GAHAN, P.B. 1984. Plant histochemistry and cytochemistry: an introduction. Academic Press, London.

GORDON, E.M. \& MCCANDLESS, E.L. 1973. Ultrastructure and histochemistry of Chondrus crispus Stack. Proceedings of Nova Scotia Institute of Science 27:111-133.

GORI, P. 1982. An investigation of carpospores in the marine red alga Gastroclonium (Roth) Ardissone (Rhodymeniales). Annals of Botany 50:451-457.

KARNOVSKY, M.J. 1965. A formaldehyde-glutaraldehyde fixative of osmolarity for use in electron microscopy. Journal of Cell Biology 27:137-138.

KONRAD-HAWKINS, E. 1974. Golgi vesicles of uncommon morphology and wall formation in the red alga, Polysiphonia. Protoplasma 80:1-14.

KUGRENS, P. \& WEST, J.A. 1972. Ultrastructure of tetrasporogenesis the parasitic red alga Levringiela gardneri (Setchell) Kylin. Phycologia 8:370-383.

LA CLAIRE, J.W. \& DAWES, C.1976. An autoradiographic and histochemical localization of sulfated polysaccharides in Eucheuma nudum (Rhodophyta). Journal of Phycology 12:368-375.

MARIANI, P., TOLOMIO, C., BALDAN, B. \& BRAGHETTA, P. 1990. Cell wall ultrastructure and cation localization in some benthic marine algae. Phycologia 29:253-262.

MCARTHUR, D.M. \& MOSS, B.L. 1977. The ultrastructure of cell walls in Enteromorpha intestinalis (L.) Link. British Phycological Journal 12:359-368.

MCCANDLESS, E.L. \& CRAIGIE, J.S. 1979. Sulfated polysaccharides in red and brown algae. Annual Review of Plant Physiology 30:41-53.

MCCULLY, M.E. 1966. Histological studies on the genus Fucus. Protoplasma 62:20-40.

MSHIGENI, K.E. 1976a. Field cultivation of Hypnea (Rhodophyta) spores for carrageenam: prospects and problems. Botanica Marina 19:227-230. 
MSHIGENI, K.E. 1976b. A note on the fate of tetrasporangial stichidia in Hypnea Lamouroux after spore release. Botanica Marina 19:313-315.

MSHIGENI, K.E. 1976c. Studies on the reproduction of selected species of Hypnea (Rhodophyta, Gigartinales) from Hawaii. Botanica Marina 19:341-346.

MSHIGENI, K.E. \& LORRI, W.S.M. 1977. Spore germination and early stages of development in Hypnea musciformis (Rhodophyta, Gigartinales). Marine Biology 42:161-164.

OLIVEIRA, E.C. 1977. Algas marinhas bentônicas do Brasil. São Paulo. Tese de Livre Docência, Universidade de São Paulo, SãoPaulo.

OURIQUES, L.C. \& BOUZON, Z.L. 2003. Ultrastructure of germinating tetraspores of Hypnea musciformis (Gigartinales, Rhodophyta). Plant Biosystems 137:193-202.

PEARSE, A.G.E. 1968. Histochemistry theoretical and applied. Little, Brown \& Company, Boston.

PUESCHEL, C.M. 1979. Ultrastructure of tetrasporogenesis in Palmaria palmata (Rhodophyta). Journal of Phycology 15:409-424.

PUESCHEL, C.M. 1982. Ultrastructural observation of tetrasporangia end conceptacles in Hildenbrandia (Rhodophyta, Hildenbrandiales) British Phycological Journal 17:333-341.

RAMARAO, K.R. 1970. Studies on growth cycle and phycocolloid content in Hypnea musciformis (Wulf) Lamouroux. Botanica Marina 13:163-165.

RAMM-ANDERSON, S.M. \& WETHERBEE, R. 1982. Structure and development of the carposporophyte of Nemalion helminthoides (Nemalionales, Rhodophyta). Journal of Phycology 18:133-141.

RAVETTO, C. 1964. Alcian blue - alcian yellow: a new method for the identification of different acidic groups. Journal of Histochemistry and Cytochemistry 12:44-45.
SAITO, R.M. \& OLIVEIRA, E.C. 1990. Chemical screening of Brazilian marine algae producing carrageenans. Hydrobiologia 204/205:585-588.

SANTISI, S. \& DE MASI, F. 1981. An electron microscopic study on tetrasporogenesis of the parasitic red alga Erythrocystis montagnei (Derb. and Sol.) Silva. Cytobios 31:163-178.

SCOTT, J. \& DIXON, P.S. 1973. Ultrastructure of tetrasporogenesis in the marine red alga Ptilota hypnoides. Journal of Phycology 9:29-46.

TAYLOR, W.R. 1960. Marine algae of the eastern tropical and subtropical coasts of the Americas. University of Michigan Press, Michigan.

TRICK, H.N. \& PUESCHEL, C.M. 1990. Cytochemistry o pit plugs in Bossiella californica (Corallinales, Rhodophyta). Phycologia 29:403-409.

TRIPODI, G. \& DE MASI, F. 1975. Cytological localization of polysaccharidic molecules in some red algae. Journal of Submicroscopy and Cytology 7:197-209.

TSEKOS, I., SCHNEPF, E. \& MAKRANTONAKIS, A. 1985. The ultrastructure of tetrasporogenesis in the marine red alga Chondria tenuissima (Good. et Woodw.) (Ceramiales, Rhodomelaceae). Annals of Botany 55:607-619.

VESK, M. \& BOROWITZKA, M. 1984. Ultrastructure of tetrasporogenesis in the coralline alga Haliptilon cuvieri (Rhodophyta). Journal of Phycology 20:501-515.

YOUNG, D.N. 1979. Ontogeny, histochemistry and fine structure of cellular inclusions in vegetative cells of Anthithamnion defectum (Ceramiaceae, Rhodophyta). Journal of Phycology 15:42-48.

YOUNG, D.N. 1980. Unusual cell wall ultrastructure in Antithamnion (Rhodophyta). British Phycological Journal 15:119-124. 